\title{
The Optimization Design of the Compressor Connecting Rod by Using of ANSYS
}

\author{
Xuebin Li, Biao Du and Kun Wang \\ School of mechanical Engineering, Anhui University of Science and Technology, Huainan Anhui China 232001
}

\begin{abstract}
A connecting rod, which a part connecting the crankshaft to piston of compressors, does linear reciprocating motion along the center of a piston inside of the cylinder, ensuring that the connecting rod qualifies the periodical changing of load and the fatigue strength and structural stiffness with better static and dynamic mechanical properties. It is an incredibly important factor to guarantee the reliability of a compressor. This study sets the connecting rod of piston-style compressors as the research object, introducing the application of the mechanical model of a connecting nod and finite element analysis in the design of connecting rod and optimizing and analyzing its structure from the perspective of finite element analysis by means of ANSYA software.
\end{abstract}

Keywords-a connecting rod; ANSYS; optimized design

\section{INTRODUCTION}

A compressor is a mechanical equipment which can convert mechanical energy into gas pressure to supply other devices with power, whereas, the strength design of a connecting rod plays an indispensable role in the design of a compressor, A highly-precise 3D model of a connecting rod shall be established to analyze its load condition and structural optimization based on it, however, due to its complex load, a large finite element analysis software is needed, which is available to analyze the problems of connecting rods and provide design of its structural optimization with technological support. Under this condition, the problems of connecting rods of compressors can be analyzed and optimization of some of structures can be made based on previous ones.

\section{The Structure OF CONNECTING ROD OF COMPRESSORS}

As is shown below picture 1 , the connecting rod is mainly composed of piston pin end, connecting rod, crank pin end, bolt, locking tads as well as nuts.

A connecting rod is mainly made by plastic forming of steel forgings with a heat treatment process to increase its strength and ensure quality. After quenching, if, without thermal refining, it is a non-quenched-tempered steel connecting rod which is made by adding such trace elements as vanadium, titanium, and niobium .After forging, the cooling is needed directly. Thus, trace elements can be precipitated as hard carbide and forging stock materials shall be reinforced. Besides, the carburizing hardening can also be adopted to improve the surface strengthening to reduce the thickness of different parts of a connecting rod, and reduce the weight with increasing the intensity simultaneously.

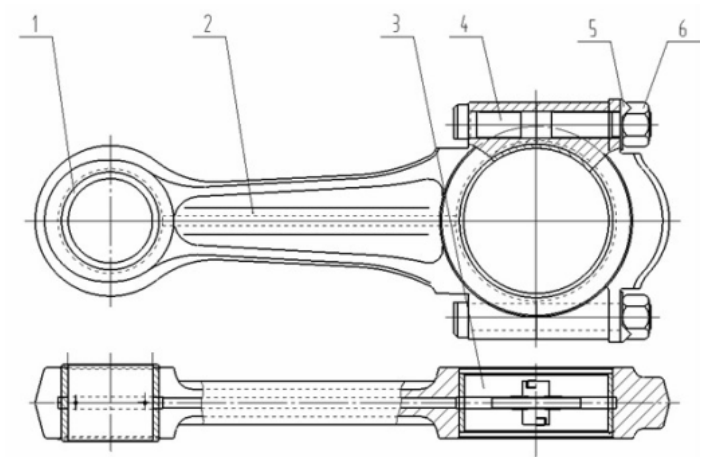

FIGURE I. THE STRUCTURE OF THE CONNECTING ROD

\section{The Optimization OF Finite ELEMENT ANALYsis}

A. The Analytical Procedures of Finite Element Methods.

(1) A model which shares something in common with the entity is established. Having imported the three-dimensional model from the analysis software, we divide the whole model into a discrete structure with a number of finite sizes, that is, commonly known as the grid division. When modifying the part of model based on the demands, it must guarantee the accuracy of the results on the premise of limited computation.

(2) The final results can be gained by means of setting up the boundary conditions of the model, choosing an appropriately invariant manner as well as using the different algorithm method.

(3) The Calculated results are often demonstrated by electronic digital display, which makes people not understand straightforwardly. Thus, we need to use software for post-processing, converting them to icon. According to the changing tendency of the chart, a more intuitive feeling can be gained and it shall get relatively higher reliability, compared with the current situation. Meanwhile, a better optimization of parts 'dimension can be achieved.

\section{B. The Establishment of 3D Modeling.}

Whether the connecting rod model of Compressors is consistent with actual situation will directly affect the accuracy of the results. in the finite element analysis, it is very necessary to simplify complex models, which will be conducive to 
reducing the operation time and have less effect on the simulation results. The assembly model of the connecting rod is shown as the following figure by means of simplifying a similar position, stretching, and cutting by a 3D software. Due to using the separate type of a connecting rod, the materials of the connecting bolts are made by the alloy steel, whose mechanical performance is better than that of 40 steel and safety coefficient is higher. That is the reason why we make the integral type of Connecting rods.

In the model of connecting rod, convex plate of the piston pin end tends to be ignored in modeling because its internal oil hole less affects the stress of the connecting rod. Thus, the same method is also adopted in the inside of oil ducts of the connecting rod . The lining bushing of the piston pin end and crank pin end of the connecting rod, which affluences the analytical results, is ignored during parts modeling. A connecting rod is made by 40 steel material , whose yield strength is $335 \mathrm{mpa}$, the elastic modulus is $200 \mathrm{gpa}$, and the ratio of the poisson is 0.3 . The modeling is shown in figure 2 .

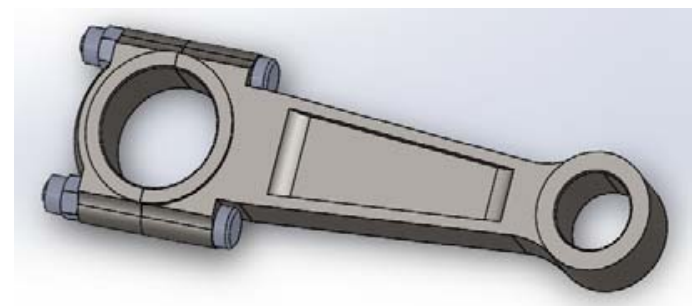

FIGURE II. THE ASSEMBLY STRUCTURE OF A CONNECTING ROD

\section{Grid Division and Stress Analysis of The Model.}

Attention should be paid in the division of grids is to balance the relationship between the numbers of grid and computing time. The complex structure characterizes complex curve and surface boundary, to which higher order element has the very good approximation. The increasing section ensures a better approximate solution, improving an accurate result. Thus, the more sections add, the more accuracy gets. Meanwhile, we need select the appropriate higher order unit. Due to the assembly divided into a tetrahedral mesh, the grid division model of the connecting rod is obtained by a special process of some unimportant parts and the contact between the parts set to be a bind one.

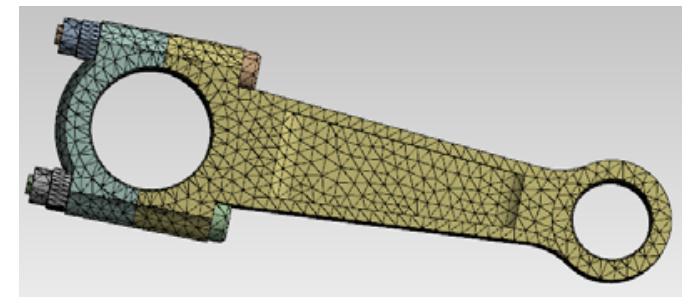

FIGURE III. THE GRID DIVISION OF A CONNECTING ROD

A connecting rod is the moving part in in the using of the compressor, whose two ends are constantly moving. In the statics analysis of the connecting rod, when both ends of it bear the same power, we need to separate them. The
Force-bearing Parts are external piston pin end and the cover of it when the connecting rod is bearing tensile force. The stress distribution of the other end is difficult to observe only through a single analysis of that of one end. Thus, we need conduct force analysis to them respectively. The circumference of one end is fixed to analyze the force distribution of the other and vice versa. in the process of compression of the compressor, the bearing part of a connecting rod is its body part. Thus, a fixed analysis of the single end makes no difference. When fixing the piston pin end, the bearing parts of a connecting rod are mainly the top of the cover and bolts. When fixing the piston pin end, its bearing part is its outer end, whose has the largest deformation. In the process of gas compression, mainly affected by the compression effect, the maximum part of the compression force of the connecting rod is the contacting part between the crank pin end and the rod body.

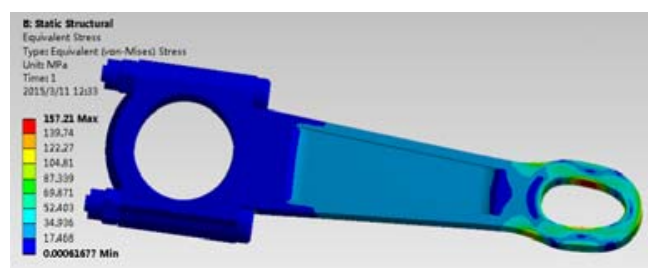

FIGURE IV. THE FIXED TENSILE STRESS NEPHOGRAM OF THE CRANK PIN END

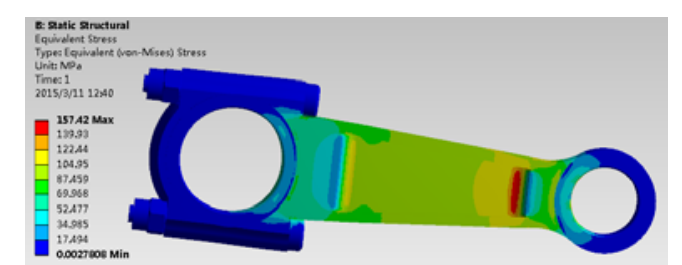

FIGURE V. THE STRESS NEPHOGRAM OF COMPRESSOR OF A CONNECTING ROD

\section{Mathematical Model of Size Optimization of ANSYS.}

Optimization analysis by the finite element analysis software ANSYS must request three variables -- the objective function, state variables and design variables, all of them are demonstrated in the form of a standard quantity.

The design variable of the Optimization analysis is independent and the form of its vector is:

$$
X=\left[x_{1}, x_{2}, \cdots, x_{n}\right]
$$

Every design variable has upper and lower limited value constrained the changing of size:

$$
\underline{x}_{i} \leq x_{i} \leq \bar{x}_{i}(\imath=1,2, \bullet \bullet \bullet, v)
$$

The targeted minimum value:

$$
\min f(x)
$$


The constraint condition:

$$
\begin{gathered}
h_{i}(x) \leq \bar{h}_{i} \quad(\mathrm{l}=1,2, \bullet \bullet \bullet, \mu 1) \quad \underline{g}_{i} \leq g_{i}(x) \quad(\imath=1,2, \bullet \bullet \bullet, \mu 2) \\
\underline{w}_{i} \leq w_{i}(x) \leq \bar{w}_{i} \quad(\imath=1,2, \bullet \bullet \bullet, \mu 3)
\end{gathered}
$$

In the formula, $f(x)$ is the objective function; $\mathrm{Gi}$, hi, wi are state variables and their designs ,including changing range; $\mathrm{m} 2$, $\mathrm{m} 3$, and $\mathrm{m} 1$ are the numbers of state variables.

Depend on state variables, design variables are changing with the change of the vector $x$ of design variables. The design scheme is the final feasible one, which is gained by satisfying all the constraint conditions, whereas, the infeasible design scheme is the one that does not meet one or more of the constraint equations .Besides, each state variable limit has its tolerance with the range of the feasible design scheme.

\section{E. Structure Optimization}

A design variable and a target volume are contained in the design of the finite element. This paper selects the quality of a connecting rod as the ultimate objective of the optimization. Besides, many factors shall be considered such as the coordination between the crankshaft and the journal or the distance between journals, together with the impact on the overall structure of the connecting rod or the whole structure of the compressor, as well as the part which bears much more force during selecting design variables. Therefore, this study chooses three factors which are more suitable for the above selection: thickness (D)of a connecting rod, depth of groove( h)of the body of a connecting rod, radius (r) of the transitional circle between the piston pin end and the body of a connecting rod. And parts mainly stress, gas compression stress as optimizing part of target. What's more, the main load-bearing of parts and stress of gas compression are considered as limited objectives of parts optimization. The variables of the model are introduced into Workbench ANSYS to set the design variables and objective variables to optimize the optimal solution and the approximate solution, which is shown in figure 1.

TABLE I. OPTIMIZE RESULTS

\begin{tabular}{cccc}
\hline $\begin{array}{c}\text { The design } \\
\text { variables }\end{array}$ & $\mathrm{d}$ & $\mathrm{h}$ & $\mathrm{r}$ \\
\hline $\begin{array}{c}\text { The name of } \\
\text { variables }\end{array}$ & $\begin{array}{c}\text { The thickness } \\
\text { of a } \\
\text { connecting } \\
\text { rod }\end{array}$ & $\begin{array}{c}\text { The depth of } \\
\text { a bar groove }\end{array}$ & $\begin{array}{c}\text { The radius of a } \\
\text { small fillet }\end{array}$ \\
$\begin{array}{c}\text { The initial } \\
\text { value }\end{array}$ & 35 & 9 & 43 \\
$\begin{array}{c}\text { Optimization } \\
\text { of } 1\end{array}$ & 24 & 7.5 & 50 \\
$\begin{array}{c}\text { Optimization } \\
\text { of } 2\end{array}$ & 20 & 6.5 & 60 \\
\hline
\end{tabular}

\section{F. Comparison of Results of Optimization.}

In analyzing the optimized data, due to the relatively complicated structure of the connecting rod, the limited amounts of the optimization of a connecting rod is not necessarily enough, meanwhile the changing of the optimized size and associated changing with it has brought changes in the link structure. The finite element software, however, is difficult to do comprehensive evaluation, people need to verify it. After all, the optimization results of the finite element can only be used as a reference, the rationality of its optimization also requires people to justify. A new three-dimensional model of the connecting rod is gained through the combination of the optimized data and the structure of the connecting rod. In addition, we need do the infinite element analysis after its modeling. As are shown in the cloud charts below, changes need to be mage in the boss connecting the crank pin end to the body of a connecting rod in the first figure. Similarly, a new design and selection of bolts need to be done in the second figure, because the hole wall of the bolt hole of the body table becomes so thin that it is difficult to adapt to the design requirements.

The compressive force enjoys a much bigger change in comparison with the changing of load-bearing of every optimized scheme, which we set as the main evaluation criterion. Besides, each optimized scheme redesigned the structure of a connecting rod and analyzed the stress. From the results we can know that:

The optimization 1 reduced $25.18 \%$, compared to the initial ones, whereas, the optimization 2 reduced $28.75 \%$, compared to the initial ones. Thus, the optimization 2 is less $4 \%$ than those of 1 , but the maximum compression force ratio of the optimization 2 is more $10 \%$ than the optimization 1 . Meanwhile the optimization 2 makes a great change in existing structures, but the effect is not very ideal. Thus, the optimization 1 should be the optimal solution after a comprehensive consideration.

\section{FIGURE VI. OPTIMIZED 1 THE BULK OF FIXED TENSILE STRESS} CLOUD
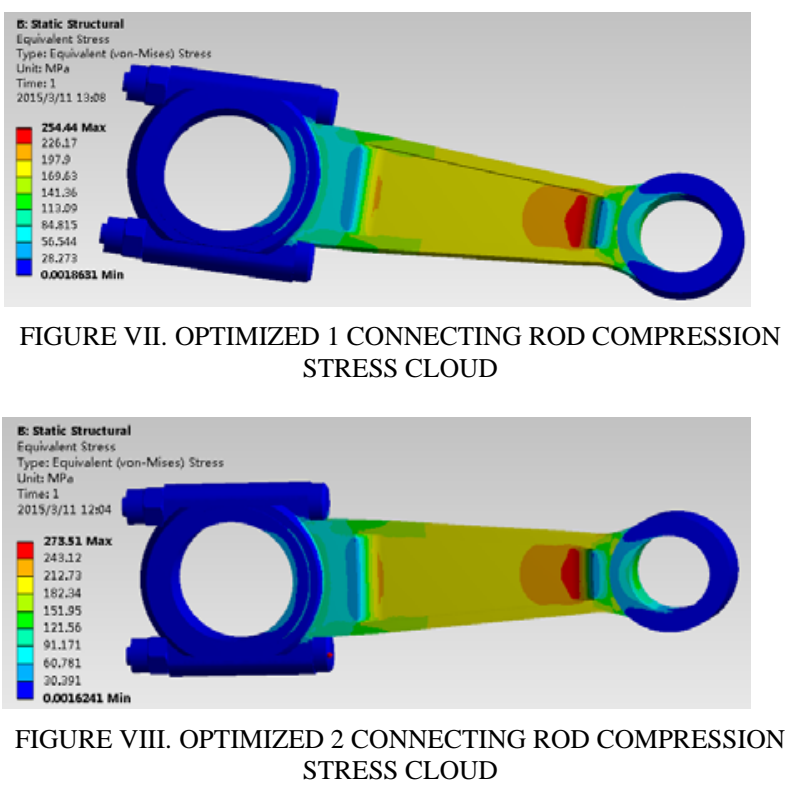

IV. SUMMARY

This study makes great achievements in gaining the overall stress distribution of the connecting rod through the finite 
element analysis and optimizes partial sizes of the connecting rod based on the data collected. According to the actual requirements, the loading and boundary conditions of the model are simplified and the diagram of stress distribution of the connecting rod is gained. The design of a connecting rod meets the requirements of the strength, which provides a reliable model with the subsequent stress analysis.

\section{REFERENCES}

[1] Manuel Vsldes, Jesus Casannova, AntoniRovira. Design of carbon pistons using Transient Heat Transfer and Stress Analysis.SAE Paper 010690,2001:17 32

[2] Brebbia CA.Adanced Analysis of Vehicles'Components using the BE Method.SAE Paper 860807,1986:101 114

[3] R.Dufour, J.Der Hagopian and M.Lalanne, Transient and steady state dynamics behaviorof single cylinder compressors:prediction and experiment, Journal of Sound and Vibration, 1995:181(1), 23 24

[4] Liansheng Li.Positive displacement compressor technology progress[J].The 3rd compressor,fan peak forum will argument,2000.

[5] Yongzhang Yu.Positive displacement compressor[M].Mechanical industry press,Beijing,2000.

[6] Shaozhong Li.Engine connecting rod production technology progress[J].Automotive technology,2000. 